\title{
An ergonomic saree design for geriatric women
}

\author{
MONISHA SINGH AND SANGITA SRIVASTAVA
}

Received: 30.08.2014; Accepted: 23.11.2014

See end of the paper for authors' affiliations MONISHA SINGH

Department of Home Science, University of Allahabad, ALLAHABAD (U.P.) INDIA Email: manusingh.singh9@ gmail.com
ABSTRACT : The human life span is increasing. The average in 80 's was 48 , in 90's increased to 59, in 2000 it was 66 and increases to 78 in 2010, bringing about a host of other related problems of care, food and clothing. Clothing is the second skin of human beings. It is an important issue throughout human life because of its protective and aesthetic functions. Clothing needs change at all ages. Due to advancement in technology the life span of human beings has been increased. Clothing needs have to be altered as per needs of the geriatric population of 70 to 85 years. Noticeable degenerative changes are visible in human body and mind during this age span. To name a few reduced mobility, stiff joints, weakness and many other diseases such as arthritis, incontinence, Alzheimer's, short term memory loss, organ failure, paralysis etc. Yet the desire to be looking and feeling normal can be resurrected with similar looking aesthetic clothing which is more functional in design and easy to wear and maintain. Saree has been redesigned for the older women having more functionality, with added comfort features.

KEY WORDS: Clothing, Geriatric, Functional

- HOW TO CITE THIS PAPER : Singh, Monisha and Srivastava, Sangita (2014). An ergonomic saree design for geriatric women. Asian J. Home Sci., 9 (2) : 641-643. 